\title{
Comparison of Some Mechanical and Physical Methods for Measurement of Residual Stresses in Brush-Plated Nickel Hardened Gold and Silver Coatings
}

\author{
Harri LILLE ${ }^{1 *}$, Jakub KÕO ${ }^{1}$, Alexander RYABCHIKOV ${ }^{1}$, Renno REITSNIK ${ }^{1}$, \\ Fjodor SERGEJEV ${ }^{2}$, Dmitri MATVEJEV ${ }^{3}$
}

${ }^{1}$ Institute of Forestry and Rural Engineering, Estonian University of Life Sciences, Kreutzwaldi 5, 51014 Tartu, Estonia

${ }^{2}$ Department of Materials Engineering, Tallinn University of Technology, Ehitajate tee 5, 19086 Tallinn, Estonia

${ }^{3}$ Moscow State University of Instrument Engineering and Computer Science, ul. Stromynka, 20, 107996 Moscow, Russia

enttp://dx.doi.org/10.5755/j01.ms.22.1.7439

Received 26 June 2014; accepted 20 August 2015

\begin{abstract}
Hard gold and silver are applied in coating owing to their high hardness, good wear and corrosion resistance for engineering application (e.g. on generators slip rings, sliding contacts and small machine parts) and are typically plated on copper (mostly), brass and bronze. The studied nickel-hardened gold and silver coatings were brush plated on open thin-walled copper ring substrates. Residual stresses in the coatings were calculated from the curvature changes of the substrates. Biaxial intrinsic residual stresses were also determined by nanoindentation testing and by the X-ray technique. The values of the residual stresses represented tensile stresses and when determined by the techniques used they were comparable within a maximum limit of measurement uncertainty. These stresses relax; the dependence of relaxation time was approximated by a linear-fractional function.

Keywords: brush-plated coatings, residual stress relaxation, layer growing curvature method, indentation technique, Xray technique.
\end{abstract}

\section{INTRODUCTION}

The properties of an engineering component are to a great extent determined by its surface properties [1]. In order to plate only small areas, with no limitation to the size of the workpiece, electrolytic brush plating is a relatively straightforward procedure. In recent time brush plating has reached industrial maturity and has gained some attention [2-4], as it is a simple processing method for selective plating of desired materials onto metallic materials without dipping the machine part or work piece into a tank of the electrolyte. Selective areas can be plated and the stylus (anode), covered with an absorbent material soaked in the electrolyte, can be moved to the substrate (cathode) or, alternatively, the substrate can be moved in relation to the fixed anode. In this case the anode is replenished with the plating solution by drops from a separatory funnel or by means of a pump, and the coating is deposited at uniform rotation speed, which guarantees a relatively homogeneous temperature of the deposition process. Consequently, the stylus is always kept in motion whenever it is in contact with the work surface. This process was schematically presented in our previous papers $[5,6]$. The solutions used in brush plating must contain metal salts at high concentrations; this permits application of higher (about 100 times) current densities and guarantees a fast deposition process in comparison with tank plating. As the plating process takes place at room temperature, no heater is required.

Brush-plated gold and silver coatings are mainly used for decorative purposes (e.g. jewellery, adornment, copper

\footnotetext{
* Corresponding author. Tel.: +372-731-3181; fax: +372-731-3156.

E-mail address: harri.lille@emu.ee (H. Lille)
}

domes of churches, musical instruments etc). For engineering use, alloying metals or nanoparticle composites are added to pure gold and silver. Alloyed hard gold and silver finish has met electric application for coatings in connector elements: generator slip rings and sliding contacts, contact springs, pin socket contacts and small parts; edges of a printed circuit board etc. These coatings have high hardness and high wear resistance and, as the contact material guarantees good switching characteristics and high electric and thermal conductivity, they have also sufficient strength. Gold coatings are mostly plated on copper, brass and bronze. A hard gold coating is sometimes plated with a nickel underlayer. The nickel underlayer has multiple functions: acting as a diffusion barrier, imparting stiffness and providing mechanical support to the contact layer [7]. Silver is often used as low-priced replacement for gold. Residual stresses arising in electrodeposited coatings can lead to detrimental effects, including a decrease in fatigue strength, cracking under service conditions, or delamination.

The nickel-hardened gold and silver coatings used in the current study were brush plated from an industrial SIFCO Dalic Solution (Gold Hard Alloy), Code SPS 5370, and Silver Hard Heavy Build, Code SPS 3083, on open thinwalled copper ring substrates $[5,6]$. In the present paper some mechanical properties of the coatings, e.g. residual stresses, surface roughness and nanohardness, which affect the service life of electrical components, were determined.

\section{EVALUATION OF RESIDUAL STRESSES IN COATINGS}

Residual stresses arise in electrodeposits and their origin is described in literature [8]. Residual stresses in the 
coatings were calculated from the curvature changes (the curvature technique is common in the electrodeposition industry, it employs long substrates to produce large, easily measurable deformation parameters) of thin-walled open ring substrates. The equation used is based on Brenner and Senderoff's concept [9], where the substrate is treated as a beam with slipping ends. In this study the equation was modified for thin coatings, to account for biaxial stresses and the shell shape of the substrate, by the coefficient $[5,6]$

$\sigma=\frac{E_{1} b_{1} F}{12 \pi b_{2} R_{0}^{2}} \cdot \frac{\left(h_{1}^{4}+4 \gamma h_{1}^{3} h_{2}\right) \Delta \delta}{h_{1} h_{2}\left(h_{1}+h_{2}\right)}$,

where $R_{0}$ is the middle radius of the substrate; $b_{1}$ and $b_{2}$ are the widths and $h_{1}$ and $h_{2}$ are the thicknesses of the substrate and coating, the coefficient

$F=\frac{1-\mu^{2} k}{\left(1-\mu^{2}\right)(1-\mu k)}$, where $k=\frac{2}{\beta b} \cdot \frac{\cosh \beta b_{1}-\cos \beta b_{1}}{\sinh \beta b_{1}+\sin \beta b_{1}}$.

The ratio k depends on $\beta=\sqrt[4]{\frac{3\left(1-\mu^{2}\right) h_{1}^{2}}{R_{0}^{2}\left(h_{1}^{4}+4 \gamma h_{1}^{3} h_{2}\right)}}$

where $\gamma=E_{2} b_{2} / E_{1} b_{1}, E_{1}$ and $E_{2}$ are the moduli of elasticity of the substrate and coating, respectively. The Poisson's ratio for the substrate and coating is assumed to be equal $\left(\mu_{1}=\mu_{2}=\mu\right), \Delta \delta$ is the measured slit change that replaces the curvature change. In comparison with previous equation $[5,6]$, where thickness $h_{2}$ is kept in the first degree, the difference is less than $5 \%$.

It has been observed that residual stresses decrease with time. An equation for approximation of the change of residual stresses, calculated from experimental data, was developed assuming that the dependence of residual stress on relaxation time is linear-fractional. The least squares approach was used to fit an equilateral hyperbola with the asymptote parallel to the coordinate axes [10]

$$
\sigma(t)=\frac{b\left(\sigma_{0}-\sigma_{\mathrm{f}}\right)}{a t+b}+\sigma_{\mathrm{f}},
$$

where $\sigma_{0}$ is the calculated residual (initial) stress of a freshly plated coating (as-deposited stress $t=0$ ); $\sigma_{\mathrm{f}}$ is calculated finishing stress; $t$ is relaxation time in days; $a$ and $b$ are constants. The calculations were made using the regression functions trendline of the MS Excel and genfit (vx, vy, vg, F) of the mathematical program Mathcad 15.0.

Localized measurement of residual stresses in the coatings was evaluated by the X-ray and instrumented indentation testing techniques. Residual stresses in the coatings were determined by the X-ray technique at the Moscow State University of Instrument Engineering and Computer Science, using the portable diffractometer DRP-3, based on the $\sin ^{2} \psi$ method [11]. Main calculations, according to Bragg's law, were made using the equations:

$n \lambda=2 d \sin \theta$;

$\sigma_{\varphi}=\frac{d_{\psi}-d_{\perp}}{d_{\perp}} \cdot \frac{E_{2}}{1+\mu_{2}}, \varphi=90-\psi$

where $n$ is the order of interference; $\lambda$ is the wavelength of the X-ray; $d$ is interplanar spacing; $\theta$ is the angle of the incidence of the X-ray beam.

Residual stresses were determined along the generatrix and in the circumferential direction using $\mathrm{CrK} \alpha$ radiation in the $\{222\}$ reflection of the coating in the middle region of the substrate.

In the present case the magnitude of the modulus of elasticity and of the nanohardness of the coatings were obtained by means of instrumented indentation using the pendulum-type nanotester MTS Nano Indenter XR®. The Oliver-Pharr method was used to determine the reduced modulus and hardness from the load displacement curves, using a tip areas function for the tip [12-15] that was carefully calibrated on fused silica according to the equation

$\frac{1}{E^{*}}=\frac{1-\mu_{2}^{2}}{E_{2}}+\frac{1-\mu^{\prime 2}}{E^{\prime}}$,

where the literature based standard values $E^{\prime}=11.43 \times 105 \mathrm{~N} / \mathrm{mm}^{2}$ and $\mu^{\prime}=0.07$ are the modulus of elasticity and the Poisson's ratio of the CVD diamond indenter, respectively [12]; $\mu_{2}=0.44$ is the Poisson's ratio for the coating, which is assumed to be equal to that for pure gold; $E^{*}$ and $E_{2}$ are the measured and the calculated moduli of elasticity of the coating materials, respectively. The measurements were conducted in a series of 30 measurements at loads of 3,5 and $10 \mathrm{mN}$, and mean values were used. The calculated average values of the elastic modulus and of nanohardness are reported.

Biaxial tensile intrinsic residual stresses were calculated from the load-penetration curves for a stressfree sample and for specimens under residual stress according to the model of Suresh and Giannakopoulos $[14,15]$ as follows:

$\frac{A_{c}}{A_{0}}=\left(1-\frac{\sigma_{r}}{H}\right)^{-1}$,

where $\sigma_{\mathrm{r}}$ is residual stress; $H$ is indentation hardness; $A_{\mathrm{c}}$ is the apparent contact area for a stressed sample and $A_{0}$ is the apparent contact area for a stress-free sample of a three-sided pyramidal Berkovich indenter used in nanoindentation. Calculation of residual stresses is presented in our previous paper [16].

The surface structure and cross section of the test pieces were studied by means of scanning electron microscopy (SEM) Zeiss EVO MA-15.

The surface topology of the coating was measured in a non-contact mode using the optical profiler Bruker Contour GT-KOX.

\section{EXPERIMENTAL PROCEDURE AND METHOD}

Nickel-hardened gold and silver coatings were brushplated from an industrial SIFCO Dalic Solution (Gold Hard Alloy), Code SPS 5370 (gold potassium cyanide,

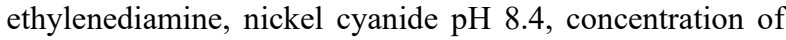
gold $100 \mathrm{~g} / 1,23 \mathrm{kt}$ ) and from Silver Hard Heavy Build, Code SPS 3083 (silver cyanide, ethylenediamine pH 11.6, concentration of silver $100 \mathrm{~g} / \mathrm{l})$, on open thin-walled copper ring substrates. A pure nickel preplate with a thickness of $0.4 \mu \mathrm{m}$ was deposited from the electrolyte with the following composition: nickel sulphate $350 \mathrm{~g} / \mathrm{l}$, formic acid $60 \mathrm{~g} / 1$, magnesium sulphate $10 \mathrm{~g} / 1 \mathrm{pH} 1.6$ [17].

Strips with dimensions $11.0 \times 0.20 \times 96.0 \mathrm{~mm}^{3}$, $11.0 \times 0.30 \times 96.0 \mathrm{~mm}^{3}$, used as the substrate, were cut from 
a copper plate and were rolled to the open ring. The surface of the substrate was polished to the roughness $R_{\mathrm{z}}=0.81 \mu \mathrm{m}$. The description of the preparation of the substrate for deposition and the plating technology can be found in the literature $[5,6]$ and the parameters are presented in Table 1.

The number in the coating code indicates the current density of which the coating was deposited onto substrate. Other signs are described below the Table 1 . The velocity of the substrate was $0.39 \mathrm{~m} / \mathrm{s}$ and room temperature was $21{ }^{\circ} \mathrm{C}$. The ratio of the anode surface to the surface to be coated was $1: 8$. The values of coatings thicknesses were measured on cross-sectional SEM micrographs.

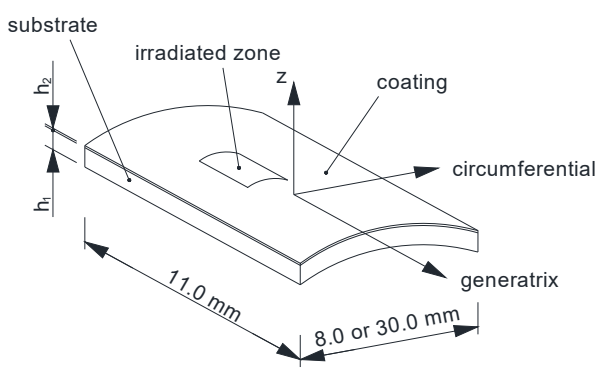

Fig. 1. Arc from ring substrate and surface coordinates

Some of the plated rings were cut along the generatrix into pieces (see Fig. 1) with an arc length of $8 \mathrm{~mm}$ for analysis of surface structure and cross section and for measuring residual stresses by the X-ray technique and with an arc length of $30 \mathrm{~mm}$ for determination of the modulus of elasticity, nanohardness and residual stresses.

\section{RESULTS AND DISCUSSION}

Residual stresses in the investigated coatings, estimated by the layer growing curvature method, as depending on relaxation time, are presented in Table 2 and in Fig. 2 a, b. Expanded uncertainty of $15.2 \%$ and $16.3 \%$ used for the gold and silver coatings, respectively, were calculated in our previous papers $[6,18]$. The values of residual stresses obtained, by nanoindentation and by the $\mathrm{X}$-ray technique using Young modulus and the Poisson's ratio for gold and silver were, $80.0 \mathrm{GPa}, 80.0 \mathrm{GPa}$ and $0.44,0.37$, respectively. The diffraction angles were $77.6^{\circ}$, $73.3^{\circ}$, and the $\psi$ tilt angles were $0^{\circ} ; 40^{\circ}, 0^{\circ} ; 40^{\circ}$, respectively. Linearity of the squared curves is accepted.

The results obtained by the curvature method show a fivefold decrease in the values of tensile stress during observation time. It is not clear why the level of asdeposited residual stress is so high, especially for the silver coatings. The obtained coefficients of the lines of approximation are different for each coating. However, the cause of this remains unclear and cannot be attributed either to deposition rate or substrate thickness.

The values of tensile stress obtained by the three methods are similar but the methods are different by nature. A strong qualitative correlation between the three methods was found to exist. The substrate curvature method yields average values of stress across the whole coating volume while the X-ray method yields only the diffraction domain in irradiated zone. However, localized measurement of residual stresses by nanoindentation is based on the size and shape of the load penetration curve. Residual stresses and hardness of plated layers are extremely important durability related issues when slip rings of generators are coated. Note that in the case of the $\mathrm{X}$-ray technique, sample preparation and instrumentation are frequently time consuming and expensive. Conversely, the nanoindentation technique is simple and requires little sample preparation or instrumentation and has several advantages.

In Fig. 3 the SEM image and linescan analysis of the cross-section of the $\mathrm{Au}$ coating on the $\mathrm{Cu}$ substrate is shown. The interfaces of the $\mathrm{Au}$ and $\mathrm{Cu}$ substrate could be clearly distinguished. The structural analysis of the samples has not been done.

Table 1. Coding (marking) of coatings, conditions of electrodeposition, measured thickness and roughness

\begin{tabular}{|l|c|c|c|c|c|c|}
\hline Coating code & Au30 & AuNi25* & Au30 & Ag20 & AgNi20* & Ag20 \\
\hline Current density, $\mathrm{A} / \mathrm{dm}^{2}$ & 30 & 25 & 30 & 20 & 20 & 20 \\
\hline Working voltage, $\mathrm{V}$ & $7.0-7.5$ & $6.5-7.0$ & $7.0-7.5$ & $5.0-5.5$ & $5.0-5.5$ & $5.0-5.5$ \\
\hline Deposition temperature, ${ }^{\circ} \mathrm{C}$ & 26 & 25 & 26 & 27 & 27 & 27 \\
\hline Deposition rate, $\mu \mathrm{m} / \mathrm{hour}$ & 33.0 & 18.0 & 75.0 & 81.0 & 72.5 & 103.3 \\
\hline Thickness of coating, $\mu \mathrm{m}$ & 5.2 & 3.6 & 5.3 & 15.5 & 13.9 & 15.5 \\
\hline Surface roughness of coating $R_{\mathrm{a}}, \mu \mathrm{m}$ & 1.97 & 1.98 & - & 1.68 & 1.78 & - \\
\hline Thickness of substrate, $\mathrm{mm}$ & 0.284 & 0.177 & 0.167 & 0.284 & 0.167 & 0.196 \\
\hline
\end{tabular}

Table 2. Coding of the coatings, calculated and determined values

\begin{tabular}{|c|c|c|c|c|c|c|c|c|}
\hline \multicolumn{3}{|l|}{ Coating code } & $\mathrm{Au} 30^{>}$ & AuNi25* & Au30 & $\operatorname{Ag} 20^{>}$ & AgNi20* & Ag20 \\
\hline \multicolumn{3}{|c|}{ Mean modulus of elasticity, GPa } & 93.3 & 86.5 & 84.3 & 85.2 & 102.2 & 79.8 \\
\hline \multirow{2}{*}{\multicolumn{2}{|c|}{$\begin{array}{l}\text { Residual stress } \\
\text { by curvature method, N/mm }\end{array}$}} & $\sigma_{0}$ & $205 \pm 31$ & $218 \pm 33$ & $266 \pm 40$ & $146 \pm 24$ & $141 \pm 23$ & $134 \pm 22$ \\
\hline & & $\sigma_{\mathrm{f}}$ & $66 \pm 10$ & $150 \pm 23$ & $116 \pm 18$ & $42 \pm 7$ & $30 \pm 5$ & $63 \pm 10$ \\
\hline \multicolumn{3}{|l|}{ Relation, $\sigma_{0} / \sigma_{\mathrm{f}}$} & 3.10 & 1.46 & 2.29 & 3.52 & 4.72 & 2.12 \\
\hline \multicolumn{3}{|c|}{ Nanohardness, GPa } & $3.20 \pm 0.37$ & $3.44 \pm 0.67$ & $1.20 \pm 0.12$ & $3.19 \pm 0.14$ & $3.34 \pm 0.26$ & $1.29 \pm 0.11$ \\
\hline \multicolumn{3}{|c|}{ Maximum indentation depth $h_{\max }$ at load $10 \mathrm{mN}, \mathrm{nm}$} & 374 & 412 & - & 414 & 376 & - \\
\hline \multicolumn{3}{|c|}{ Contact depth $h_{\mathrm{c}}$ at load of $10 \mathrm{mN}, \mathrm{nm}$} & 347 & 325 & - & 323 & 343 & - \\
\hline \multirow[t]{2}{*}{ Residual stress } & \multicolumn{2}{|c|}{$\begin{array}{l}\text { by nano-indentation technique } \\
\sigma_{\mathrm{r}}, \mathrm{N} / \mathrm{mm}^{2}\end{array}$} & $154.0 \pm 3.2$ & $227.0 \pm 4.5$ & - & $68.0 \pm 1.4$ & $103.0 \pm 2.0$ & - \\
\hline & \multicolumn{2}{|c|}{ by X-ray technique $\sigma_{\varphi}, \mathrm{N} / \mathrm{mm}^{2}$} & - & - & $95 \pm 25$ & - & - & $45 \pm 20$ \\
\hline
\end{tabular}




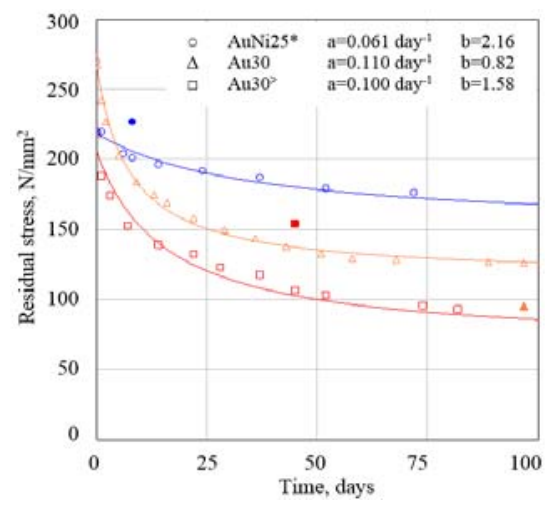

a

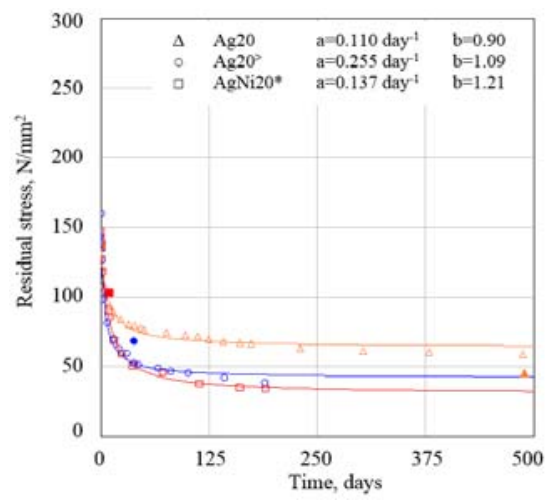

$\mathrm{b}$

Fig. 2. Residual stresses in the gold (a) and silver (b) coatings, depending on relaxation time, and the line of approximation; residual stresses determined by nanoindentation (solid dots) and the by X-ray technique (solid triangle) according to relaxation time

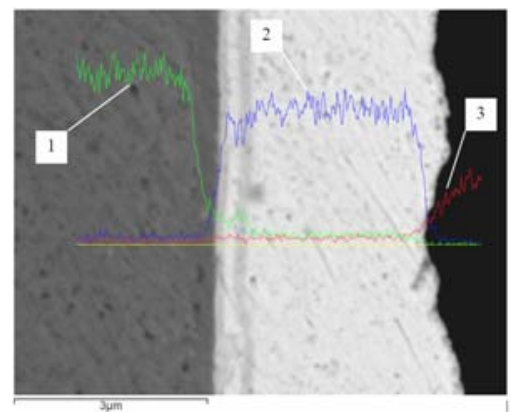

Fig. 3. Raster graphics image for evaluation of components ratio $(1-\mathrm{Cu}, 2-\mathrm{Au}$ and $3-\mathrm{C})$

The typical surface morphology and the cross sections of the gold and silver coatings, studied by means of SEM, are presented (Fig. 4, Fig. 5).

Brush-plated coatings have a fine crystalline nanostructure which is caused, on the one hand, by the high deposition current and, on the other hand, depend on deposition rate. These coatings contain carbon impurities originating from the graphite anode, which can have an effect on the mechanical properties of the coating material.

In the future more experimental effort, aimed to evaluate the microstructure of the coatings during relaxation of residual stresses, is needed.

Fig. 6 and Fig. 7 show a typical topology of the gold and silver coatings studied by an optical profiler.

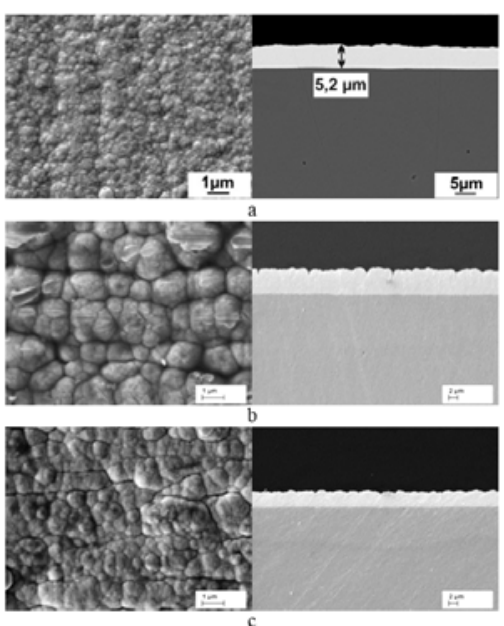

Fig. 4. The morphology and cross sections of the gold coatings: $\mathrm{a}-\mathrm{Au} 30 ; \mathrm{b}-\mathrm{Au} 30^{>} ; \mathrm{c}-\mathrm{AuNi} 25^{*}$

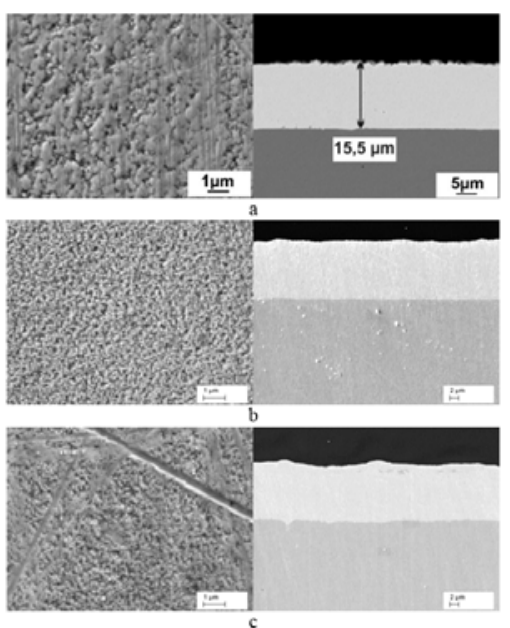

Fig. 5. The morphology and cross sections of the silver coatings: $\mathrm{a}-\mathrm{Ag} 20 ; \mathrm{b}-\mathrm{AgNi20} * \mathrm{c}-\mathrm{Ag} 20^{>}$
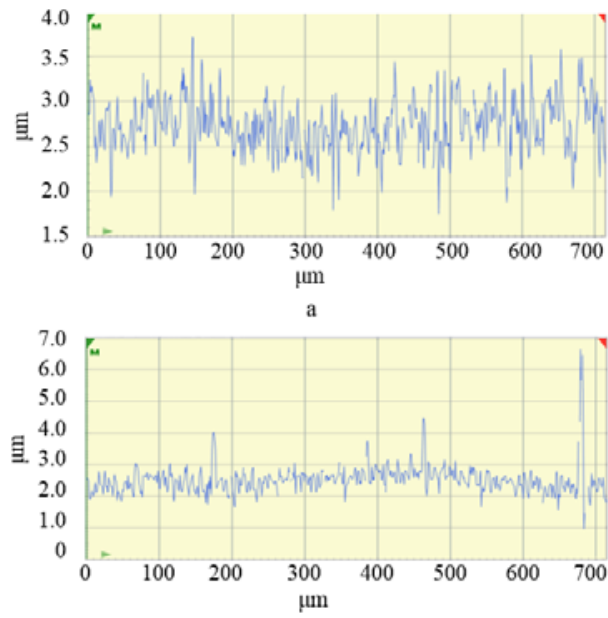

b

Fig. 6. The surface topology of the gold coatings: a-Au30; b-AuNi25*

In Fig. 4 b, c and Fig. $5 \mathrm{~b}$ the profile of the cross section of the coating obtained by SEM corresponds to the surface topology shown in Fig. 6 a,b and Fig. 7 a, b, 
respectively. It can be seen that if grain size in surface morphology is coarser then the intensity of jags is higher.

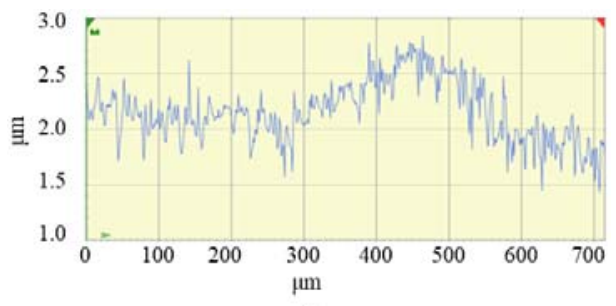

a

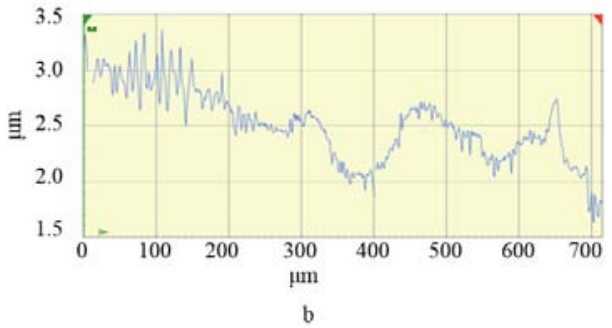

Fig. 7. The surface topology of the silver coatings: $\mathrm{a}-\mathrm{Ag} 20^{>}$; $\mathrm{b}-\mathrm{AgNi} 20^{*}$

The average roughness of the investigated coatings is presented in Table 1. It is evident that when coating thickness increases then also the roughness of coated surface increases more than twofold; therefore, finishing is needed for obtaining mirror surface.

\section{CONCLUSIONS}

The values of tensile residual stresses in the gold and silver coatings, obtained by the three methods, were comparable and they decreased significantly, in particular, during the first weeks.

The average values of the moduli of elasticity and of the nanohardness of the gold and silver coatings, obtained by instrumented indentation, fluctuated to a great extent and were comparable.

Brush-plated coatings had a fine crystalline nanostructure which was caused by the high deposition current and by the short-term growth of the formed grains.

The micrograph of the cross-section of the coatings revealed graphite particles deposited from the anode.

\section{Acknowledgements}

This study was supported by the Estonian Ministry of Education and Research, and by the target-financed project SF0140091s08. The authors wish to thank Ph.D. Valdek Mikli for SEM analysis.

\section{REFERENCES}

1. Gering, J., Bell, T., Farr, J.P.G., Mountford, R., Ryan, J. Structure and Wear Resistance of Brush Plated Nickel Transactions - Institute of Metal Finishing 73 (3) 1995: pp. $82-84$.

2. Rubinstein, M. Electrochemical Metallizing. Van Norstrand Reinhold Company Inc., New York, 1987.

3. Hui, W.H., Liu J.J., Dennis, J.K. Microstructure and Hardness of Brush Plated Ni-Fe-W-P-S Alloy Journal of Applied Electrochemistry 27 1997: pp. 105-108.
http://dx.doi.org/10.1023/A:1026431302815

4. Wu, B., Xu, B., Zhang, B., Lu, Y. Preparation and

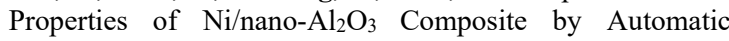
Brush Plating Surface and Coating Technology 201 2007: pp. $6933-6939$.

5. Lille, H., Kõo, J., Ryabchikov, A. On the Investigation of Residual Stresses in Brush Plated Silver Coatings Materials Science (Medžiagotyra) 14 (3) 2008: pp. 226-229.

6. Lille, H., Kõo, J., Ryabchikov, A., Veinthal, R., Mikli, V., Sergejev, F. Determination of Residual Stresses, Modulus of Elasticity and Nanohardness in Brush-Plated Gold and Silver Coatings on Copper Substrate Materials Science (Medžiagotyra) 18 (1) 2012: pp. 51-56.

7. Corti, C., Holliday, R. Gold: Science and Applications. CRC Press, 2010.

8. Weil, R. The Origin of Stresses in Electrodeposits. Review of the Literature Dealing with Stress in Electrodeposited Metals. Part I Plating 57 (12) 1970: pp. 1231-1237.

9. Brenner, A., Senderoff, $\mathbf{S}$. Calculation of Stress in Electrodeposits from the Curvature of a Plated Strip Journal of Research of the National Bureau of Standards 42 (2) 1949: pp. $105-123$.

10. Virchenko, I.A., Lyashko, I.I., Shvetsov, K.I. Handbook: Graphs of the Functions. Naukova Dumka, Kiev, 1979 (in Russian).

11. Lyutsau, A.V., Zvonkov, A.D., Kotelkin, A.V., Matveev, D.B., $\quad$ Nikitina, S.V., Ibraimov, N.S., Malagodi, D., Srinivasan, S. Use of Kumakhovs Optics in Portable Diffractometer for Stress-Strain Plus Elemental Analysis Abstracts of XIX Congress and General Assembly of the International Union of Crystallography 2002: p. 74.

12. Klein, C., Cardinale, G. Young's modulus and Poisson's ratio of CVD diamond Proceedings of Society of Photo-optical Instrumentation Engineers 1759 1992: pp. $178-193$.

13. Zhang, Y., Tan, E.P.S., Sow, C.H., Lim, C.T Nanomechanical Characterization of One-Dimensional Nanostructures Micro and Nano Mechanical Testing of Materials and Devices, Yang, F., Li. J.C.M. (eds.). Springer, 2009: pp. $105-120$.

14. Chen, X., Yan, J., Karlsson, A.M. On the Determination of Residual Stress and Mechanical Properties by Indentation Materials Science and Engineering: A 416 2006: pp. $139-149$.

15. Jang, J. Estimation of Residual Stress by Instrumented Indentation: A Review Journal of Ceramic Processing Research 10 (3) 2009: pp. 391-400.

16. Lille, H., Kõo, J., Ryabchikov, A., Reitsnik, R., Sergejev, F., Mikli, V. Comparative Analysis of Residual Stresses Determined by Various Methods in Brush-Plated Hard Gold and Silver Coatings Key Engineering Materials 604 2014: pp. 8-11.

17. Lille, H., Kõo, J., Ryabchikov, A. A Comparative Analysis of Residual Stresses in Brush-Plated Nickel Galvanic Coatings Using Substrate Deformation and X-Ray Diffraction Methods XII International Baltic Conference. Engineering Materials \& Tribology 2004: pp. 170-174.

18. Lille, H., Kõo, J., Ryabchikov, A., Laaneots, $R$. Relaxation of Residual Stresses in Brush-Plated Gold Coating Proceedings of the 6th International Conference of DAAAM Baltic, Industrial Engineering 2008: pp. 491-496. 